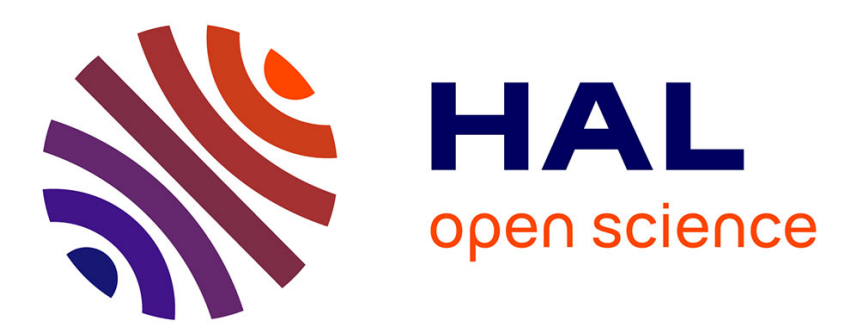

\title{
Exact Analytical Method for Magnetic Field Computation in the Air Gap of Cylindrical Electrical Machines Considering Slotting Effects
}

\author{
Thierry Lubin, Smail Mezani, Abderrezak Rezzoug
}

\section{- To cite this version:}

Thierry Lubin, Smail Mezani, Abderrezak Rezzoug. Exact Analytical Method for Magnetic Field Computation in the Air Gap of Cylindrical Electrical Machines Considering Slotting Effects. IEEE Transactions on Magnetics, 2010, 46 (4), pp.1092-1099. 10.1109/TMAG.2009.2036257 . hal-00557548

\section{HAL Id: hal-00557548 \\ https://hal.science/hal-00557548}

Submitted on 13 Nov 2011

HAL is a multi-disciplinary open access archive for the deposit and dissemination of scientific research documents, whether they are published or not. The documents may come from teaching and research institutions in France or abroad, or from public or private research centers.
L'archive ouverte pluridisciplinaire HAL, est destinée au dépôt et à la diffusion de documents scientifiques de niveau recherche, publiés ou non, émanant des établissements d'enseignement et de recherche français ou étrangers, des laboratoires publics ou privés. 


\title{
Exact Analytical Method for Magnetic Field Computation in the Air-Gap of Cylindrical Electrical Machines Considering Slotting Effects
}

\author{
Thierry Lubin, Smail Mezani, and Abderrezak Rezzoug. \\ Groupe de Recherche en Electrotechnique et Electronique de Nancy, \\ University Henri Poincaré, Nancy, FRANCE
}

\begin{abstract}
This paper deals with an analytical method for magnetic field calculation in the air-gap of cylindrical electrical machines including slotting effects. The analytical method is based on the resolution of the two-dimensional Laplace's equation in polar coordinates by the separation of variables technique. The originality of the proposed model is to take into account the mutual influence of slots on the airgap magnetic field. The proposed method is sufficiently general to be used as a tool for air-gap magnetic field calculation of slotted electrical machines as reluctance or permanent magnet motors or actuators. Magnetic field and electromagnetic torque computed with the proposed analytical method are validated through finite element analysis.
\end{abstract}

Index Terms - Analytical solution, electrical machines, magnetic field, slotting effect.

\section{INTRODUCTION}

$I^{\prime}$ N ANALYTICAL modeling of electrical machines, one of the most difficult task is to take into account the slotting effect in air-gap magnetic field prediction. As electromagnetic torque results from the interaction between the rotor and the stator through the magnetic field in the air-gap space, an accurate knowledge of the air-gap magnetic field distribution is necessary. The presence of stator or/and rotor slots have a large influence on the air-gap magnetic field distribution and therefore on the electromagnetic torque. The consequences can be torque ripples causing vibration, noise and speed fluctuations.

The air-gap magnetic field with slotting effects can be evaluated by a variety of techniques including analytical or semi-analytical methods as well as numerical techniques like finite elements or boundary integral methods. Finite elements give accurate results considering geometric details and nonlinearity of magnetic materials. However, this method is computer time consuming and poorly flexible for the first step of design stage of electrical machines.

Analytical methods are useful tools for first evaluation of electrical motors performances and for design optimization since continuous derivatives issued from the analytical solution are of great importance in most optimization methods.

A significant number of publications on the analytical solution of the air-gap magnetic field in slotted machines can be found in the literature [2]-[15]. The publications focus essentially on the determination of cogging torque in permanent magnet motors of radial field topology. Two analytical methods are mainly developed. The first one concerns the use of conformal mapping to consider slotting effects [2]-[5]. This method has an important drawback since it is assumed that the slot width is much smaller than its height. The second method consists of analytical solution of Laplace or Poisson equations in the different sub-domains (magnet, air-gap and slots) by applying the boundary conditions on the interface between sub-domains [6]-[15].

To the authors' knowledge, the most complete analytical models using the sub-domain method are given in [13]-[15]. Analytical solutions of the field equation are computed in the air-gap and in the slots of a permanent magnet motor. However, the sub-domain models in [13]-[15] are developed for a single slot, so the interaction between neighboring slots is ignored. In fact, good results are obtained [14] for air gap flux density distribution and cogging torque waveform except for an 8-pole/12 slot PM motor for which the hypothesis cited above is not verified.

Compared to previously sub-domain model based on single slot hypothesis, the proposed model includes the mutual influence of slots on the air-gap magnetic field.

The emphasis of this paper is to show the effectiveness of the proposed analytical method and not to study a particular electrical machine. The developed tool can obviously treat problems like electromagnetic torque or cogging torque estimation in conventional electrical actuators ie. permanent magnet and switched reluctance motors, but it is sufficiently general to handle more complicated structures like magnetic gears [18].

The paper is organized as follows. The problem description and the assumptions of the model are presented in section II. Section III describes the analytical method for magnetic field calculation in the air-gap and in the slot domains. The analytical results are then verified with finite-element method in section IV. 


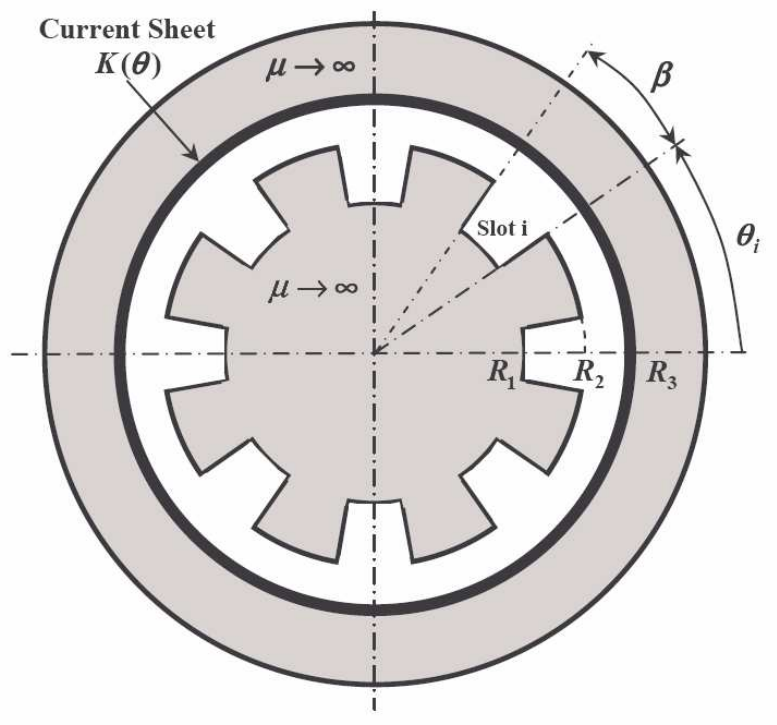

Fig. 1. Geometry of the studied model (with $Q=8$ and $\theta_{0}=0 \mathrm{rad}$ ).

\section{PROBLEM DESCRIPTION AND ASSUMPTIONS}

The geometric representation of the model used to study the slotting effects on the air-gap magnetic field of cylindrical electrical machines is shown in Fig. 1. The geometrical parameters are the inner radius of the rotor yoke $R_{1}$, the radius of the rotor surface $R_{2}$ and the stator bore radius $R_{3}$. The rotor has $Q$ slots. The slot opening angle is $\beta$. The angular position of the $i$-th rotor slot is defined as

$$
\theta_{i}=-\frac{\beta}{2}+\frac{2 i \pi}{Q}+\theta_{0} \quad \text { with } \quad 1 \leq i \leq Q
$$

where $\theta_{0}$ is the angular position of the rotor.

In order to simplify the theoretical analysis, we assume that the source term is represented by a current sheet distributed over the stator inner radius $\left(\mathrm{r}=R_{3}\right)$. The expression of the current sheet is

$$
\boldsymbol{K}(\theta)=\sum_{m=1}^{\infty} K_{m} \cdot \cos (m p(\theta-\alpha)) \cdot \boldsymbol{e}_{z}
$$

where $K_{m}$ is the peak value of the $m$-th harmonic component of the current sheet in $(\mathrm{A} / \mathrm{m}), \alpha$ is the angular position of the current sheet and $p$ is the number of pole pairs. $\boldsymbol{e}_{z}$ is the unit vector along the $\mathrm{z}$ axis.

All the calculus are made by using the following assumptions:

- End effects are neglected.

- The stator and rotor iron cores are infinitely permeable.

- No current in the slots.

- The rotor slots have radial sides.
The whole structure is divided into the air-gap region (domain $I$ ) which has an annular shape and $Q$ slots (numbered from 1 to $Q$ ). The $i$-th slot is shown in Fig. 2. A magnetic vector potential formulation is used in $2 \mathrm{D}$ polar coordinates to describe the problem. According to the adopted assumptions, the magnetic vector potential has only one component along the z-direction and only depends on the $r$ and $\theta$ coordinates. The notations used in the paper are

$$
\begin{array}{ll}
\boldsymbol{A}_{\boldsymbol{I}}=A_{I}(r, \theta) \cdot \boldsymbol{e}_{z} & \text { for the air-gap domain } \\
\boldsymbol{A}_{\boldsymbol{i}}=A_{i}(r, \theta) \cdot \boldsymbol{e}_{z} & \text { for the } i \text {-th slot domain }
\end{array}
$$

\section{ANALYTICAL SOLUTION}

The solution of any partial differential equation (PDE) depends on the domain in which the solution is to be valid as well as the boundary conditions that the solution must satisfy. By using separation of variables, we now consider the solution of Laplace's equation for the slots and the air-gap. For the sake of clarity and simplicity of the general solutions in the different domains, we adopt the following notations

$$
\begin{aligned}
& P_{z}(x, y)=\left(\frac{x}{y}\right)^{z}+\left(\frac{y}{x}\right)^{z} \\
& E_{z}(x, y)=\left(\frac{x}{y}\right)^{z}-\left(\frac{y}{x}\right)^{z}
\end{aligned}
$$

\section{A. General Solution of Laplace's equation in the $i$-th slot domain}

The $i$-th slot domain and the associated boundary conditions are shown in Fig. 2. We have to solve the Laplace's equation in a domain of inner radius $R_{1}$ and outer radius $R_{2}$ delimited by the angles $\theta_{i}$ and $\theta_{i}+\beta$

$$
\frac{\partial^{2} A_{i}}{\partial r^{2}}+\frac{1}{r} \frac{\partial A_{i}}{\partial r}+\frac{1}{r^{2}} \frac{\partial^{2} A_{i}}{\partial \theta^{2}}=0 \text { for }\left\{\begin{array}{l}
R_{1} \leq r \leq R_{2} \\
\theta_{i} \leq \theta \leq \theta_{i}+\beta
\end{array}\right.
$$

The boundary conditions for the $i$-th slot domain are (the tangential component of the magnetic field at the sides and at the bottom of the slot are null)

$$
\begin{aligned}
& \left.\frac{\partial A_{i}}{\partial \theta}\right|_{\theta=\theta_{i}}=0 \quad \text { and }\left.\quad \frac{\partial A_{i}}{\partial \theta}\right|_{\theta=\theta_{i}+\beta}=0 \\
& \left.\frac{\partial A_{i}}{\partial r}\right|_{r=R_{1}}=0
\end{aligned}
$$

The continuity condition between the $i$-th slot and the airgap leads to

$$
A_{i}\left(R_{2}, \theta\right)=A_{I}\left(R_{2}, \theta\right)
$$




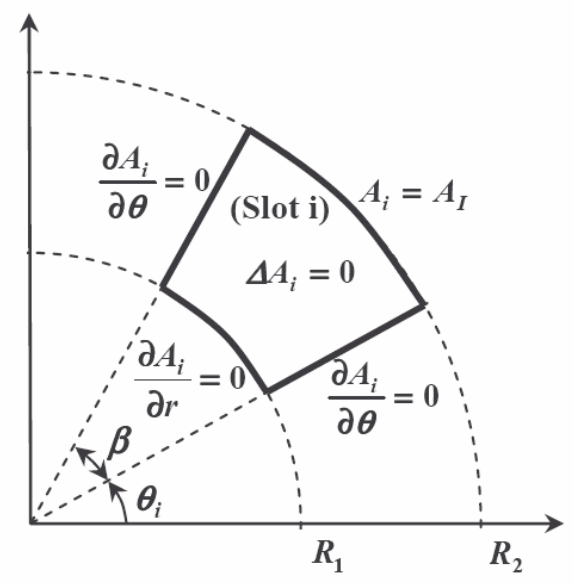

Fig. 2. $i$-th slot domain with its boundary conditions.

The general solution of (7) can be found by using the method of the separation of variables, so the solution can be written as

$A_{i}(r, \theta)=\rho_{i}(r) \Theta_{i}(\theta)$

Substituting (11) into (7), we obtain two ordinary differential equations where $\lambda(\lambda \in \mathfrak{R})$ is the separation constant

$\Theta_{i}^{\prime \prime}-\lambda \Theta_{i}=0$

$r^{2} \rho_{i}^{\prime \prime}+r \rho_{i}^{\prime}+\lambda \rho_{i}=0$

Using (11), the boundary conditions (8) become

$$
\Theta_{i}{ }^{\prime}\left(\theta_{i}\right)=0 \quad \text { and } \quad \Theta_{i}{ }^{\prime}\left(\theta_{i}+\beta\right)=0
$$

We are now confronted to the problem of finding the values of the parameter $\lambda$ for which non-trivial solutions of (12) satisfying the boundary conditions (14) exist (Sturm-Liouville problem). Under the latest condition, the values of the parameter $\lambda$ are called eigenvalues and the solutions are called eigenfunctions. A general method to compute the eigenvalues and eigenfunctions for a Sturm-Liouville problem is given in [1]. The eigenvalues of the problem (12), (14) are

$\lambda_{0}=0$

$\lambda_{k}=-\left(\frac{k \pi}{\beta}\right)^{2}$ with $k=1,2,3, \ldots$.

The eigenfunctions corresponding to $\lambda_{0}$ and $\lambda_{k}$ are given by

$$
\begin{aligned}
& \Theta_{i 0}(\theta)=1 \\
& \Theta_{i k}(\theta)=\cos \left(\frac{k \pi}{\beta}\left(\theta-\theta_{i}\right)\right)
\end{aligned}
$$

For $\lambda_{0}$ and $\lambda_{k}$, the general solutions of (13) can be written as

$\rho_{i 0}(r)=A_{0}^{i}+B_{0}^{i} \ln r$

$\rho_{i k}(r)=A_{k}^{i} r^{-\frac{k \pi}{\beta}}+B_{k}^{i} r^{\frac{k \pi}{\beta}}$

where $A_{0}^{i}, B_{0}^{i}, A_{k}^{i}$ and $B_{k}^{i}$ are arbitrary constants.

Writing the general solution as a linear combination of the previous solutions, we have

$A_{i}(r, \theta)=\Theta_{i 0}(\theta) \rho_{i 0}(r)+\sum_{k=1}^{\infty} \Theta_{i k}(\theta) \rho_{i k}(r)$

therefore

$$
\begin{aligned}
& A_{i}(r, \theta)=A_{0}^{i}+B_{0}^{i} \ln r \\
& +\sum_{k=1}^{\infty}\left(A_{k}^{i} r^{-\frac{k \pi}{\beta}}+B_{k}^{i} r^{\frac{k \pi}{\beta}}\right) \cdot \cos \left(\frac{k \pi}{\beta}\left(\theta-\theta_{i}\right)\right)
\end{aligned}
$$

Considering the boundary condition (9) and the continuity condition (10), the general solution of the magnetic vector potential in the $i$-th slot domain can be written as

$$
A_{i}(r, \theta)=A_{0}^{i}+\sum_{k=1}^{\infty} A_{k}^{i} \cdot \frac{P_{k \pi / \beta}\left(r, R_{1}\right)}{P_{k \pi / \beta}\left(R_{1}, R_{2}\right)} \cdot \cos \left(\frac{k \pi}{\beta}\left(\theta-\theta_{i}\right)\right)
$$

where $P_{k \pi / \beta}\left(r, R_{1}\right)$ is defined by (5).

The constants $A_{0}^{i}, A_{k}^{i}$ are determined using a Fourier series expansion of the air-gap magnetic vector potential $A_{I}$ over the slot interval $\left[\theta_{i}, \theta_{i}+\beta\right]$ at $r=R_{2}$.

$$
\begin{aligned}
& A_{0}^{i}=\frac{1}{\beta} \int_{\theta_{i}}^{\theta_{i}+\beta} A_{I}\left(R_{2}, \theta\right) \cdot d \theta \\
& A_{k}^{i}=\frac{2}{\beta} \int_{\theta_{i}}^{\theta_{i}+\beta} A_{I}\left(R_{2}, \theta\right) \cdot \cos \left(\frac{k \pi}{\beta}\left(\theta-\theta_{i}\right)\right) \cdot d \theta
\end{aligned}
$$

The expression for the coefficient $A_{k}^{i}$ is given in the appendix (the calculus of $A_{o}^{i}$ is not necessary to compute the flux density expression).

The radial and the tangential components of the flux density in the $i$-th slot are related to the magnetic vector potential by the well-known relations

$$
\begin{aligned}
& B_{i r}=\frac{1}{r} \frac{\partial A_{i}}{\partial \theta} \\
& B_{i \theta}=-\frac{\partial A_{i}}{\partial r}
\end{aligned}
$$




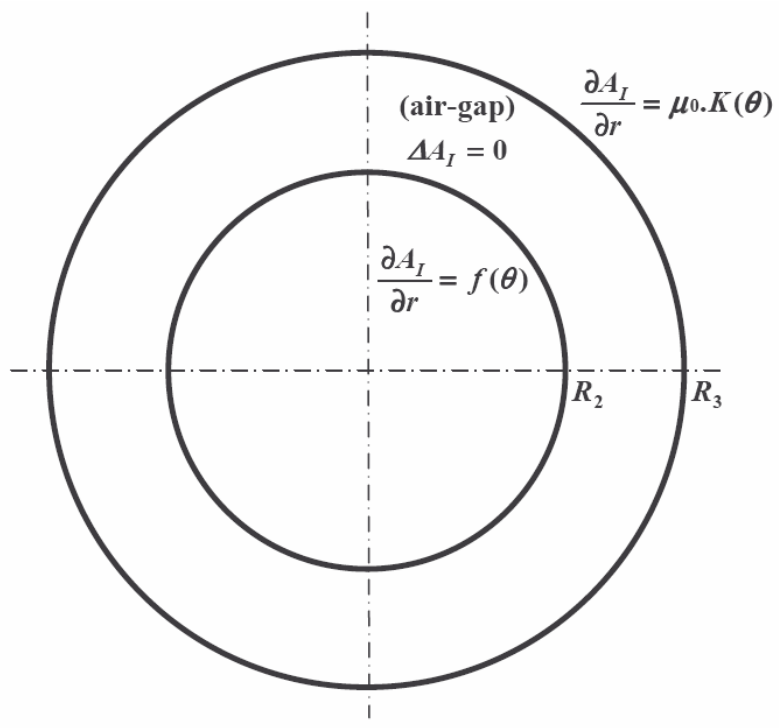

Fig. 3. Air-gap domain with its boundary conditions.

\section{B. General solution of Laplace's equation in the air-gap}

The air-gap domain and the associated boundary conditions are shown in Fig. 3. The problem to solve is

$\frac{\partial^{2} A_{I}}{\partial r^{2}}+\frac{1}{r} \frac{\partial A_{I}}{\partial r}+\frac{1}{r^{2}} \frac{\partial^{2} A_{I}}{\partial \theta^{2}}=0 \quad$ for $\quad\left\{\begin{array}{l}R_{2} \leq r \leq R_{3} \\ 0 \leq \theta \leq 2 \pi\end{array}\right.$

Considering the current sheet $K(\theta)$ and infinite permeability of the stator back iron, the boundary condition for the air-gap domain at $r=R_{3}$ is

$\left.\frac{\partial A_{I}}{\partial r}\right|_{r=R_{3}}=\mu_{0} K(\theta)$

where $\mu_{0}$ is the vacuum permeability.

The boundary condition at the internal radius $r=R_{2}$ is more difficult to handle because of the existence of the rotor slots as shown in Fig. 1. Considering the continuity of the tangential magnetic field at the interface between the rotor slots and the air-gap and considering that the tangential magnetic field is equal to zero elsewhere (infinite permeability of the rotor back iron), the boundary condition at $r=R_{2}$ can be written as

$\left.\frac{\partial A_{I}}{\partial r}\right|_{r=R_{2}}=f(\theta)$

with

$\begin{array}{ll}f(\theta)=\left.\frac{\partial A_{i}}{\partial r}\right|_{r=R_{2}} & \text { for } \quad \theta_{i} \leq \theta \leq \theta_{i}+\beta \\ f(\theta)=0 & \text { elsewhere }\end{array}$

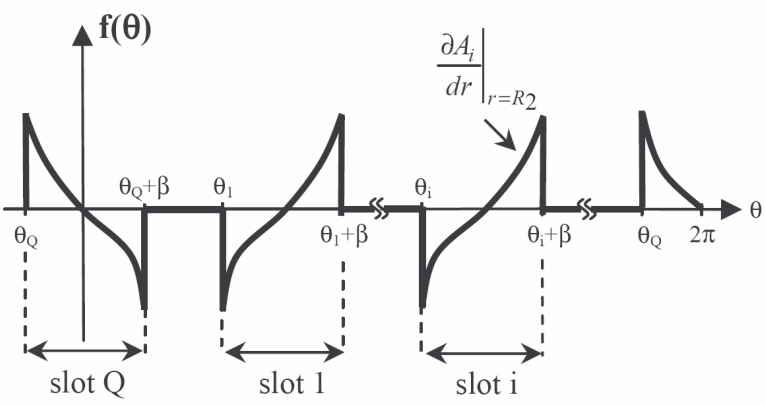

Fig. 4. Schematic representation of $f(\theta)$ along the air-gap at $r=R_{2}$.

where $A_{i}(r, \theta)$ is the magnetic vector potential in the $i$-th slot given by (23). The distribution of $f(\theta)$ along the air-gap domain interval $[0,2 \pi]$ is schematically shown in Fig. 4.

The general solution of (28) is well known [1] (periodic Sturm-Liouville problem in an annulus). By taking into account the boundary conditions (29) and (30), the general solution of the magnetic vector potential in the air-gap domain can be written as

$$
\begin{aligned}
& A_{I}(r, \theta)=A_{0}^{I} \\
& +\sum_{n=1}^{\infty}\left(A_{n}^{I} \frac{R_{2}}{n} \frac{P_{n}\left(r, R_{3}\right)}{E_{n}\left(R_{2}, R_{3}\right)}+B_{n}^{I} \frac{R_{3}}{n} \frac{P_{n}\left(r, R_{2}\right)}{E_{n}\left(R_{3}, R_{2}\right)}\right) \cos (n \theta) \\
& +\sum_{n=1}^{\infty}\left(C_{n}^{I} \frac{R_{2}}{n} \frac{P_{n}\left(r, R_{3}\right)}{E_{n}\left(R_{2}, R_{3}\right)}+D_{n}^{I} \frac{R_{3}}{n} \frac{P_{n}\left(r, R_{2}\right)}{E_{n}\left(R_{3}, R_{2}\right)}\right) \sin (n \theta)
\end{aligned}
$$

where $n$ is a positive integer, $P_{n}\left(r, R_{3}\right)$ and $E_{n}\left(R_{2}, R_{3}\right)$ are defined by (5) and (6). The coefficients $A_{n}^{I}, B_{n}^{I}, C_{n}^{I}$ and $D_{n}^{I}$ are determined using a Fourier series expansions of $\mu_{0} K(\theta)$ and $f(\theta)$ over the air-gap interval $[0,2 \pi]$

$A_{n}^{I}=\frac{2}{2 \pi} \int_{0}^{2 \pi} f(\theta) \cos (n \theta) \cdot d \theta$

$B_{n}^{I}=\frac{2}{2 \pi} \int_{0}^{2 \pi} \mu_{0} K(\theta) \cos (n \theta) \cdot d \theta$

$C_{n}^{I}=\frac{2}{2 \pi} \int_{0}^{2 \pi} f(\theta) \sin (n \theta) \cdot d \theta$

$D_{n}^{I}=\frac{2}{2 \pi} \int_{0}^{2 \pi} \mu_{0} K(\theta) \sin (n \theta) \cdot d \theta$

The expressions for the coefficients $A_{n}^{I}, B_{n}^{I}, C_{n}^{I}$ and $D_{n}^{I}$ are given in the appendix.

The flux density in the air-gap domain is given by

$\boldsymbol{B}_{\boldsymbol{I}}=B_{I r}(r, \theta) \cdot \boldsymbol{e}_{\boldsymbol{r}}+B_{I \theta}(r, \theta) \cdot \boldsymbol{e}_{\boldsymbol{\theta}}$

where the radial and the tangential components $B_{I r}, B_{I \theta}$ are 
respectively

$$
\begin{aligned}
& B_{I r}(r, \theta)= \\
& +\sum_{n=1}^{\infty}-\left(A_{n}^{I} \frac{R_{2}}{r} \frac{P_{n}\left(r, R_{3}\right)}{E_{n}\left(R_{2}, R_{3}\right)}+B_{n}^{I} \frac{R_{3}}{r} \frac{P_{n}\left(r, R_{2}\right)}{E_{n}\left(R_{3}, R_{2}\right)}\right) \sin (n \theta) \\
& +\sum_{n=1}^{\infty}\left(C_{n}^{I} \frac{R_{2}}{r} \frac{P_{n}\left(r, R_{3}\right)}{E_{n}\left(R_{2}, R_{3}\right)}+D_{n}^{I} \frac{R_{3}}{r} \frac{P_{n}\left(r, R_{2}\right)}{E_{n}\left(R_{3}, R_{2}\right)}\right) \cos (n \theta)
\end{aligned}
$$

$$
\begin{aligned}
& B_{I \theta}(r, \theta)= \\
& +\sum_{n=1}^{\infty}-\left(A_{n}^{I} \frac{R_{2}}{r} \frac{E_{n}\left(r, R_{3}\right)}{E_{n}\left(R_{2}, R_{3}\right)}+B_{n}^{I} \frac{R_{3}}{r} \frac{E_{n}\left(r, R_{2}\right)}{E_{n}\left(R_{3}, R_{2}\right)}\right) \cos (n \theta) \\
& +\sum_{n=1}^{\infty}-\left(C_{n}^{I} \frac{R_{2}}{r} \frac{E_{n}\left(r, R_{3}\right)}{E_{n}\left(R_{2}, R_{3}\right)}+D_{n}^{I} \frac{R_{3}}{r} \frac{E_{n}\left(r, R_{2}\right)}{E_{n}\left(R_{3}, R_{2}\right)}\right) \sin (n \theta)
\end{aligned}
$$

\section{Electromagnetic torque}

The electromagnetic torque is obtained using the Maxwell stress tensor. A circle of radius $R_{e}$ in the air-gap is taken as the integration path so the electromagnetic torque is expressed as follows

$T_{e}(\alpha)=\frac{L R_{e}^{2}}{\mu_{0}} \int_{0}^{2 \pi} B_{I r}\left(R_{e}, \theta, \alpha\right) \cdot B_{I \theta}\left(R_{e}, \theta, \alpha\right) \cdot d \theta$

where $L$ is the axial length and $\alpha$ the angular position of the current sheet as defined in (2). According to (38) and (39), the analytical expression for the electromagnetic torque becomes

$T_{e}(\alpha)=\frac{\pi L R_{e}^{2}}{\mu_{0}} \sum_{n=1}^{\infty}\left(W_{n} X_{n}+Y_{n} Z_{n}\right)$

where

$$
\begin{aligned}
& W_{n}=-A_{n}^{I} \frac{R_{2}}{R_{e}} \frac{P_{n}\left(R_{e}, R_{3}\right)}{E_{n}\left(R_{2}, R_{3}\right)}-B_{n}^{I} \frac{R_{3}}{R_{e}} \frac{P_{n}\left(R_{e}, R_{2}\right)}{E_{n}\left(R_{3}, R_{2}\right)} \\
& X_{n}=-C_{n}^{I} \frac{R_{2}}{R_{e}} \frac{E_{n}\left(R_{e}, R_{3}\right)}{E_{n}\left(R_{2}, R_{3}\right)}-D_{n}^{I} \frac{R_{3}}{R_{e}} \frac{E_{n}\left(R_{e}, R_{2}\right)}{E_{n}\left(R_{3}, R_{2}\right)} \\
& Y_{n}=C_{n}^{I} \frac{R_{2}}{R_{e}} \frac{P_{n}\left(R_{e}, R_{3}\right)}{E_{n}\left(R_{2}, R_{3}\right)}+D_{n}^{I} \frac{R_{3}}{R_{e}} \frac{P_{n}\left(R_{e}, R_{2}\right)}{E_{n}\left(R_{3}, R_{2}\right)} \\
& Z_{n}=-A_{n}^{I} \frac{R_{2}}{R_{e}} \frac{E_{n}\left(R_{e}, R_{3}\right)}{E_{n}\left(R_{2}, R_{3}\right)}-B_{n}^{I} \frac{R_{3}}{R_{e}} \frac{E_{n}\left(R_{e}, R_{2}\right)}{E_{n}\left(R_{3}, R_{2}\right)}
\end{aligned}
$$

\section{APPLICATION EXAMPLES}

In order to validate the proposed model, the analytical results have been compared with 2D finite element simulations obtained from COMSOL Multiphysics. The mesh in the air-gap and in the slot regions has been refined until convergent results are obtained.

Thereafter, results are given for a one-slot rotor and for a four-slot rotor. The geometrical parameters given in Table I are considered in the simulation studies. The analytical solutions in the air-gap and in the slot domains have been computed with a finite number of harmonic terms $N$ and $K$ as indicated in Table I.

\section{A. Results for a one-slot rotor $(Q=1)$}

Figure 5 shows the magnetic flux lines for the one-slot rotor with $\alpha=0$ and $\theta_{0}=135^{\circ}$. Only the fundamental component of the current sheet is considered. The number of pole pairs is fixed to $p=1$. The value of $K_{1}$ is given in Table I. The current sheet expression is then

$\boldsymbol{K}(\theta)=K_{1} \cos \theta \cdot \boldsymbol{e}_{z}$

The flux density distributions in the middle of the air-gap domain $(r=7.5 \mathrm{~cm})$ and in the middle of the slot domain $(r=5.5 \mathrm{~cm})$ are plotted respectively in Fig. 6 and in Fig. 7.

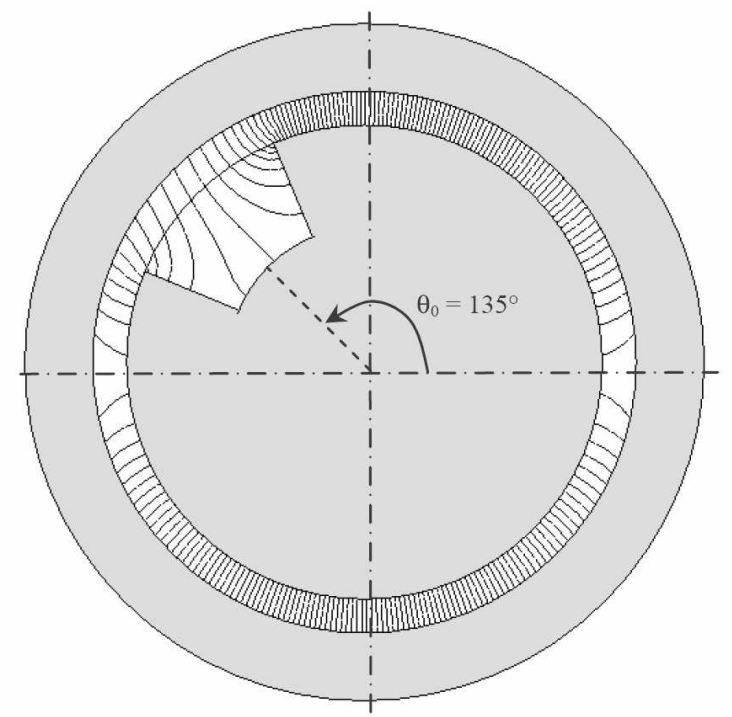

Fig. 5. Magnetic flux line distribution for the one-slot rotor computed using FEM with $\alpha=0$ and $\theta_{0}=135^{\circ}$.

TABLE I

PARAMETERS OF THE MODEL

\begin{tabular}{lll}
\hline \hline Symbol & \multicolumn{1}{c}{ Quantity } & \multicolumn{1}{c}{ value } \\
\hline$R_{1}$ & Inner radius of the rotor yoke & $4 \mathrm{~cm}$ \\
$R_{2}$ & Radius of the rotor surface & $7 \mathrm{~cm}$ \\
$R_{3}$ & Stator bore radius & $8 \mathrm{~cm}$ \\
$L$ & Axial length & $10 \mathrm{~cm}$ \\
$\beta$ & Slot opening & $\pi / 4 \mathrm{rad}$ \\
$K_{1}$ & Peak value of the fundamental component of & $1.10^{5} \mathrm{~A} / \mathrm{m}$ \\
& the current sheet & 50 \\
$\mathrm{~N}$ & $\begin{array}{l}\text { Number of harmonics used for magnetic field } \\
\text { calculation in the air-gap domain }\end{array}$ & \\
$K$ & $\begin{array}{l}\text { Number of harmonics used for magnetic field } \\
\text { calculation in the slot domain }\end{array}$ & 50 \\
\hline \hline
\end{tabular}


From the figures, the effect of the slots is very clear. In fact, one can see the distortion of the flux density waveforms at the vicinity of the slot opening while they are practically sinusoidal elsewhere.

The analytical result for the electromagnetic torque computed with (41) is given in Fig. 8. We can observe an excellent agreement with the torque deduced from FEM.

Zhu et al. [16] have shown that the cogging torque waveform of a permanent magnet machine can be analytically synthesized from the cogging torque waveform of a single slot machine. However, they used finite-element analysis to compute the cogging torque waveform for a one slot machine. With the proposed method, it is possible to compute analytically the cogging torque waveform for a one-slot machine by considering a cylindrical permanent magnet region instead of the current sheet.

\section{B. Results for a four-slot rotor $(Q=4)$}

For the four-slot rotor analysis, only the fundamental component of the current sheet is considered in the simulation.

The number of pole pairs is fixed to $p=2$. The current sheet expression is then

$$
\boldsymbol{K}(\theta)=K_{1} \cos 2(\theta-\alpha) \cdot \boldsymbol{e}_{z}
$$

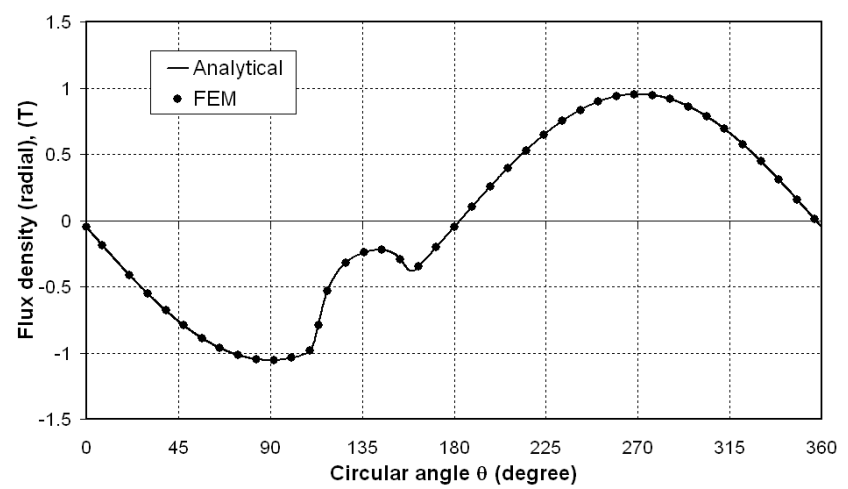

(a)

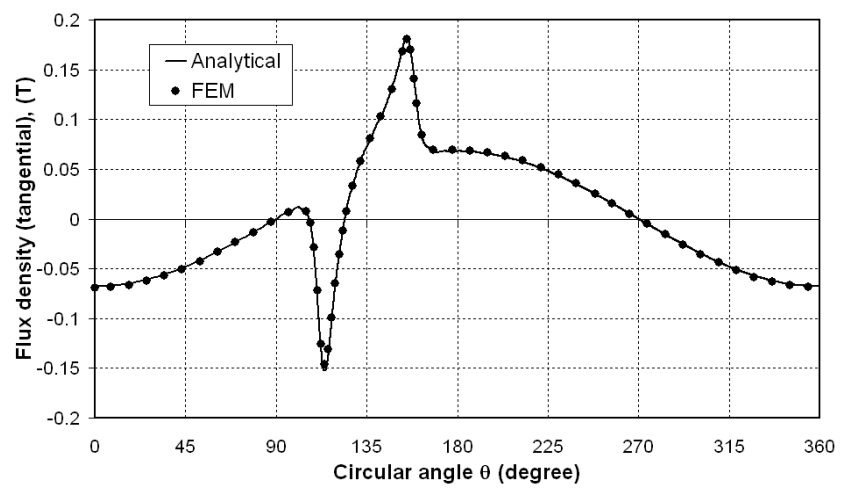

(b)

Fig. 6. One-slot rotor; Flux density distribution for radial component (a) and tangential component (b) in the middle of the air-gap $(r=7.5 \mathrm{~cm})$.
Figures 9, 10 show the magnetic flux lines for the four-slot rotor computed respectively for $\alpha=0$ and $\alpha=\pi / 4$.

The flux density distributions in the middle of the air-gap domain (at $r=7.5 \mathrm{~cm}$ ) for $\alpha=0$ and $\alpha=\pi / 4$ are plotted respectively in Fig. 11 and Fig. 12. One can observe very good agreement between the analytical and finite element predictions for both radial and tangential components.

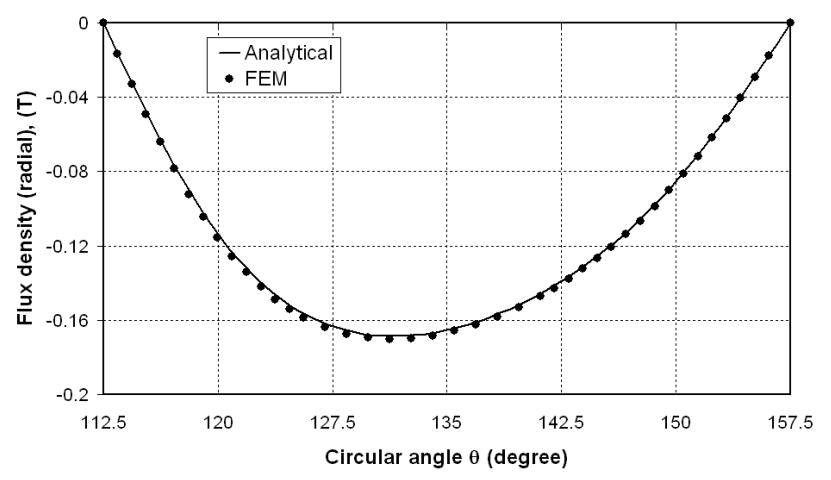

(a)

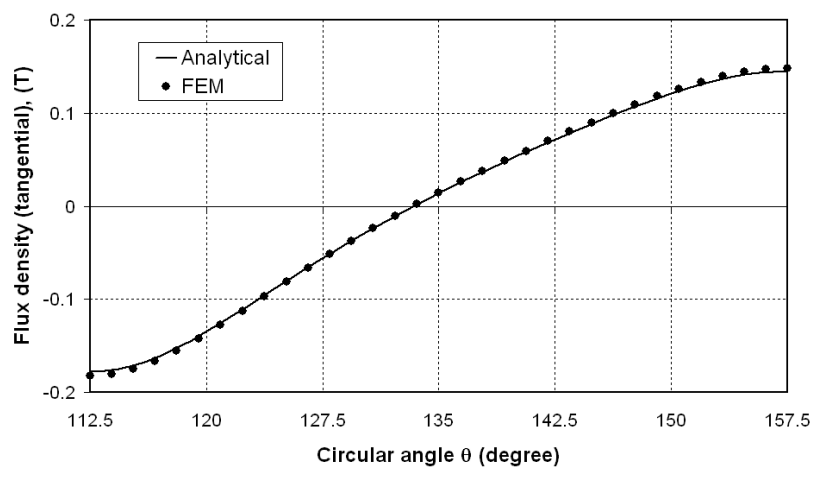

(b)

Fig. 7. One-slot rotor; Flux density Distribution for radial component (a) and tangential component (b) in the middle of the slot $(r=5.5 \mathrm{~cm})$.

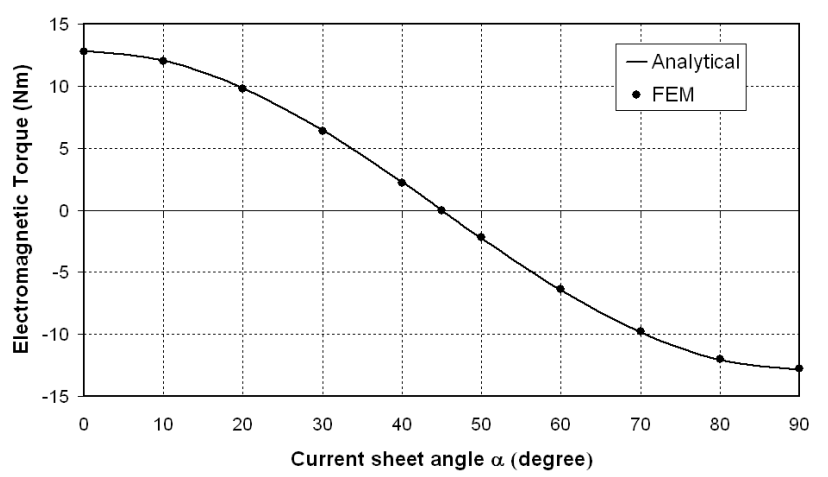

Fig. 8. Electromagnetic torque versus angular position of the current sheet for the one-slot rotor. 
The tangential component of the air-gap flux density at $r=R_{2}$ computed with the analytical method is given in Fig. 13. Because of the discontinuity of the tangential component, a large number of harmonics ( $K=N=200)$ are required to represent correctly the flux density. The small oscillations in Fig. 13 are due to the well-known Gibbs' phenomenon.

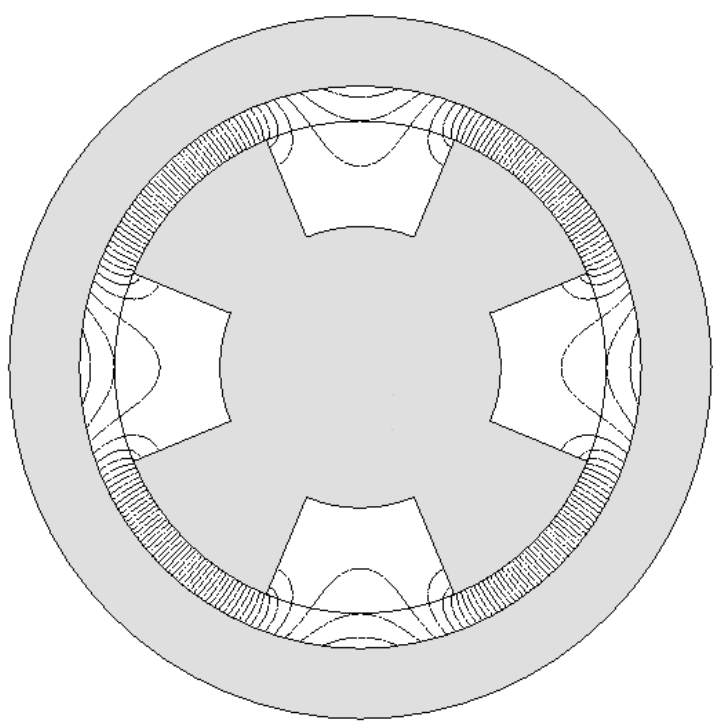

Fig. 9. Magnetic flux line distribution for the four-slot rotor computed using FEM for $\alpha=0$ and $\theta_{0}=0$

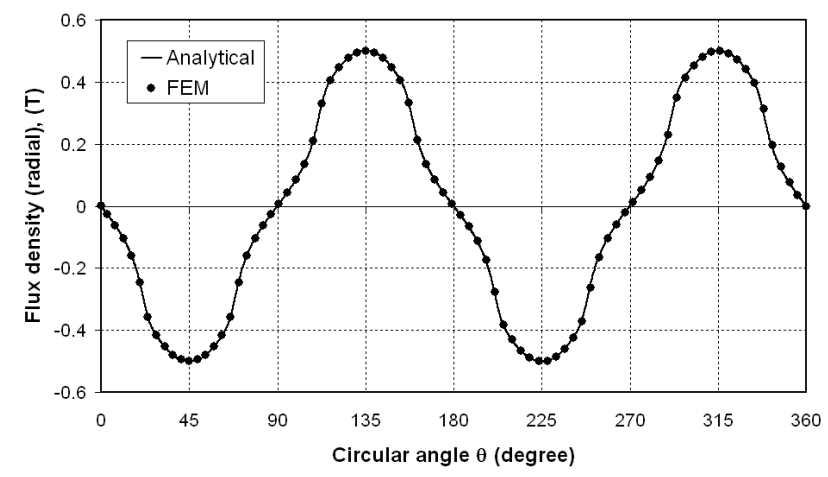

(a)

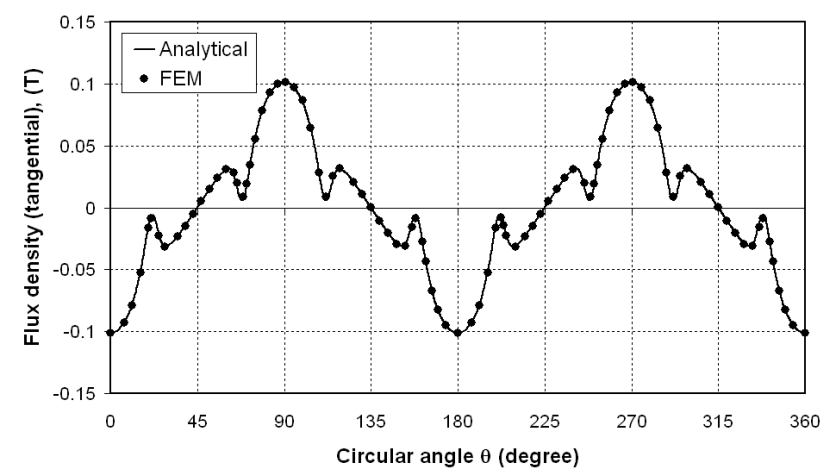

(b)

Fig. 11. Four-slot rotor; Flux density distribution for radial component (a) and tangential component (b) in the middle of the air-gap for $\alpha=0$.
The analytical result for the electromagnetic torque computed with (41) is given in Fig. 14. We can observe a good agreement with the torque deduced from FEM. The torque characteristic shown in Fig. 14 corresponds to the classical result obtained for a 4-pole Synchronous Reluctance Motor [17].

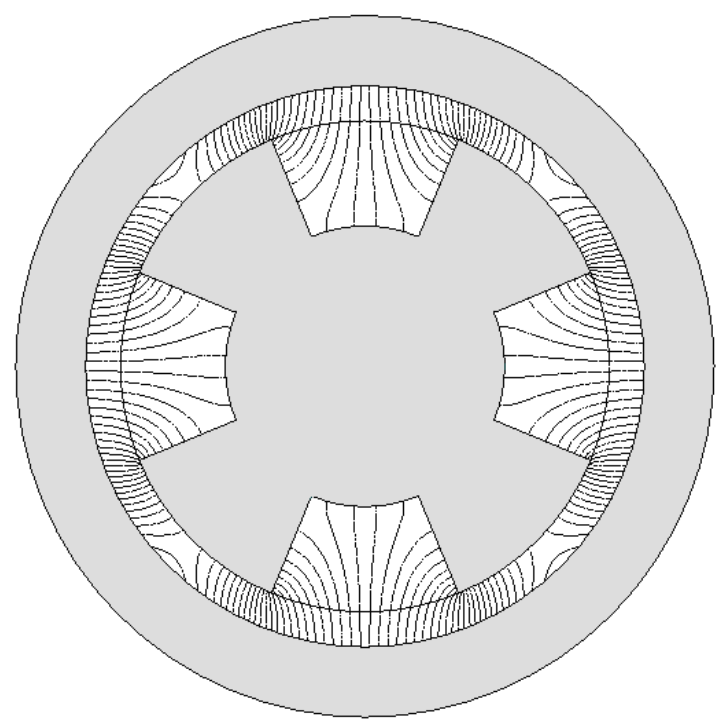

Fig. 10. Magnetic flux line distribution for the four-slot rotor computed using FEM for $\alpha=\pi / 4$ rad and $\theta_{0}=0$.

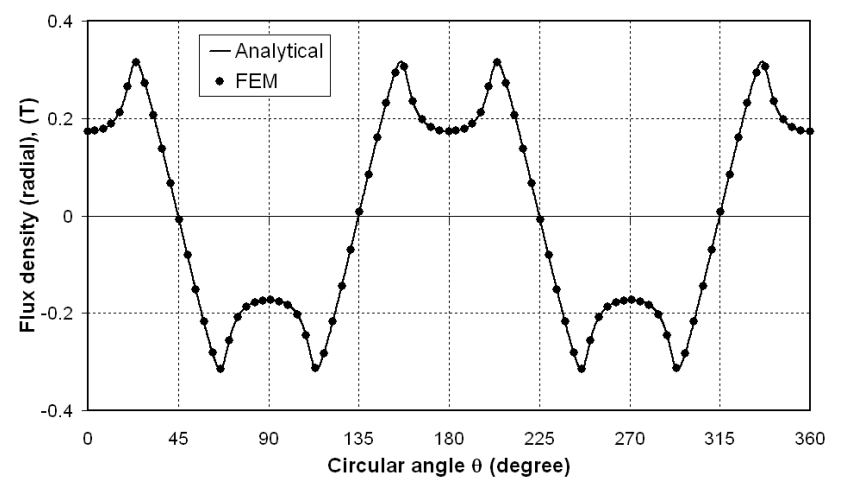

(a)

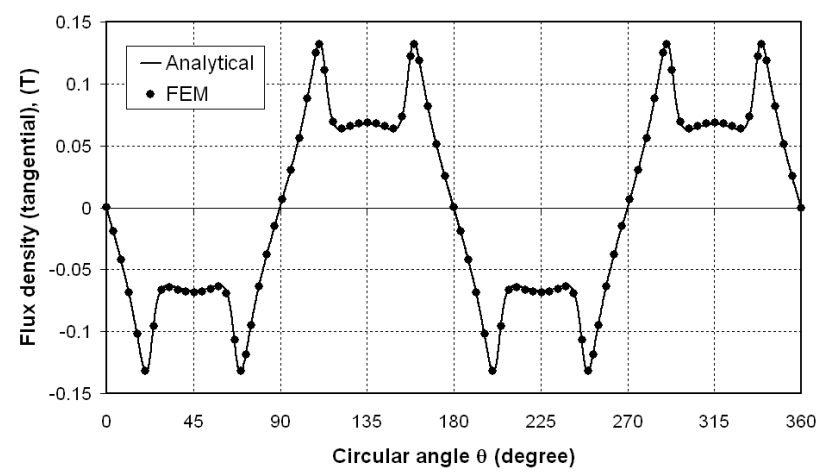

(b)

Fig. 12. Four-slot rotor; Flux density distribution for radial component (a) and tangential component (b) in the middle of the air-gap for $\alpha=\pi / 4 \mathrm{rad}$. 


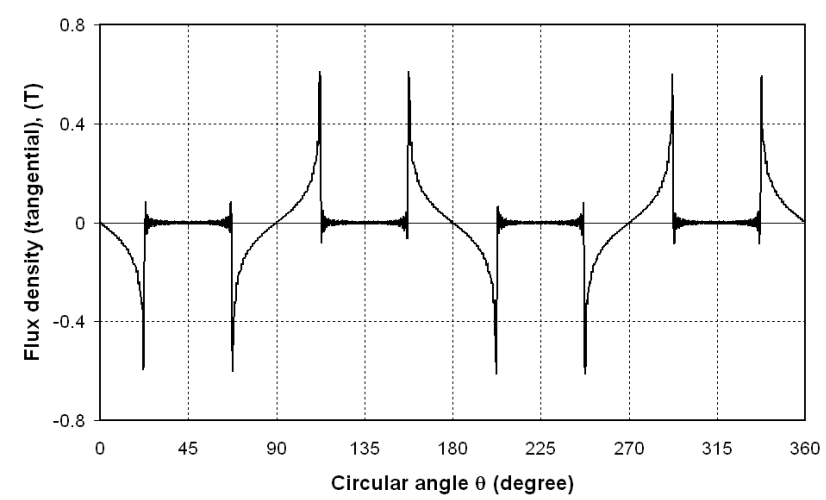

Fig. 13. Flux density distribution (tangential component) on the air-gap surface $\left(r=R_{2}\right)$ for $\alpha=\pi / 4 \mathrm{rad}$.

\section{CONCLUSION}

In this paper, an exact analytical method for computing the air-gap field distribution in cylindrical electrical machines considering slotting effects has been presented. The Laplace's equation in polar coordinates has been solved by the technique of separation of variables in the slots and air-gap domains. Compared to previously sub-domain model based on single slot hypothesis, the proposed model includes the mutual influence of slots on the air-gap magnetic field. The model developed in this work has been validated by finite-element analysis. The methodology described in this paper can be used as a preliminary tool for the resolution of many problems like analytical estimation of electromagnetic torque in reluctance machine or cogging torque estimation in permanent magnet machine. The analytical model described in this paper will be extended in future works to predict the electromagnetic torque in magnetic gear.

\section{APPENDIX}

For the determination of the integration coefficients (25), (33) and (35), we have to calculate integrals of the form

$$
\begin{aligned}
& f(k, n, i)=\int_{\theta_{i}}^{\theta_{i}+\beta} \cos (n \theta) \cdot \cos \left(\frac{k \pi}{\beta}\left(\theta-\theta_{i}\right)\right) \cdot d \theta \\
& g(k, n, i)=\int_{\theta_{i}}^{\theta_{i}+\beta} \sin (n \theta) \cdot \cos \left(\frac{k \pi}{\beta}\left(\theta-\theta_{i}\right)\right) \cdot d \theta
\end{aligned}
$$

The development of (A.1) and (A.2) gives the following functions that will be used in the expressions of the integration coefficients

$$
\begin{aligned}
& \text { - for } k \pi \neq n \beta \\
& f(k, n, i)=\frac{-n \beta^{2}\left((-1)^{k} \sin n\left(\beta+\theta_{i}\right)-\sin \left(n \theta_{i}\right)\right)}{k^{2} \pi^{2}-n^{2} \beta^{2}}
\end{aligned}
$$

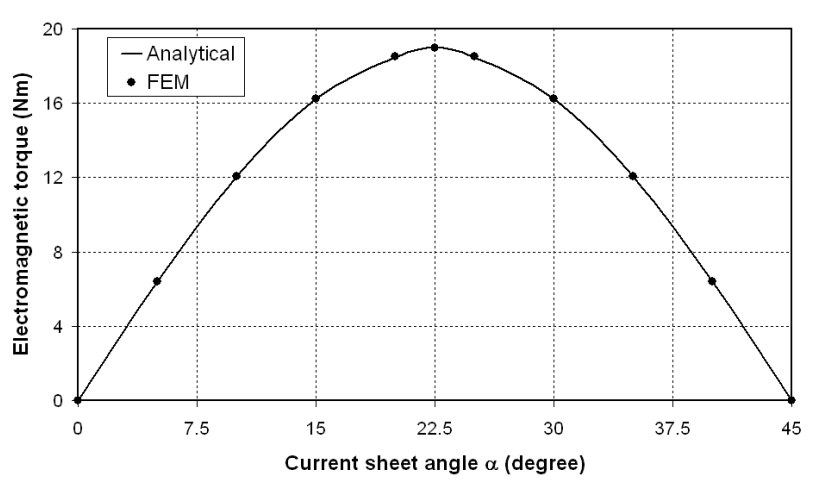

Fig. 14. Electromagnetic torque versus angular position of the current sheet for 4-slot rotor.

$g(k, n, i)=\frac{n \beta^{2}\left((-1)^{k} \cos n\left(\beta+\theta_{i}\right)-\cos \left(n \theta_{i}\right)\right)}{k^{2} \pi^{2}-n^{2} \beta^{2}}$

- for $k \pi=n \beta$

$f(k, n, i)=\frac{\beta}{2}\left(\cos \left(n \theta_{i}\right)+\frac{1}{2 k \pi}\left(\sin n\left(\theta_{i}+2 \beta\right)-\sin \left(n \theta_{i}\right)\right)\right)$

$g(k, n, i)=\frac{\beta}{2}\left(\sin \left(n \theta_{i}\right)-\frac{1}{2 k \pi}\left(\cos n\left(\theta_{i}+2 \beta\right)-\cos \left(n \theta_{i}\right)\right)\right)$

- Expressions of the coefficients $A_{n}^{I}, B_{n}^{I}, C_{n}^{I}$ and $D_{n}^{I}$ for the air-gap domain

The development of (34) and (36) gives

$\begin{array}{lll}B_{n}^{I}=\sum_{m=1}^{\infty} \mu_{0} K_{m} \cos (m p \alpha) & \text { for } & n=m p \\ B_{n}^{I}=0 & \text { for } & n \neq m p\end{array}$

$\begin{array}{lll}D_{n}^{I}=\sum_{m=1}^{\infty} \mu_{0} K_{m} \sin (m p \alpha) & \text { for } & n=m p \\ D_{n}^{I}=0 & \text { for } & n \neq m p\end{array}$

The coefficient $A_{n}^{I}$ and $C_{n}^{I}$ defined in (33) and (35) can be written as

$$
\begin{aligned}
& A_{n}^{I}=\left.\frac{2}{2 \pi} \sum_{i=1}^{Q} \int_{\theta_{i}}^{\theta_{i}+\beta} \frac{\partial A_{i}}{\partial r}\right|_{r=R_{2}} \cdot \cos (n \theta) \cdot d \theta \\
& C_{n}^{I}=\left.\frac{2}{2 \pi} \sum_{i=1}^{Q} \int_{\theta_{i}}^{\theta_{i}+\beta} \frac{\partial A_{i}}{\partial r}\right|_{r=R_{2}} \cdot \sin (n \theta) \cdot d \theta
\end{aligned}
$$


where $\mathrm{Q}$ is the number of rotor slots. The development of (A.9) and (A.10) gives

$$
\begin{aligned}
& A_{n}^{I}=\sum_{i=1}^{Q} \sum_{k=1}^{\infty}-A_{k}^{i} \frac{k}{\beta R_{2}} \frac{E_{k \pi / \beta}\left(R_{1}, R_{2}\right)}{P_{k \pi / \beta}\left(R_{1}, R_{2}\right)} \cdot f(k, n, i) \\
& C_{n}^{I}=\sum_{i=1}^{Q} \sum_{k=1}^{\infty}-A_{k}^{i} \frac{k}{\beta R_{2}} \frac{E_{k \pi / \beta}\left(R_{1}, R_{2}\right)}{P_{k \pi / \beta}\left(R_{1}, R_{2}\right)} \cdot g(k, n, i)
\end{aligned}
$$

- Expression of the coefficient $A_{k}^{i}$ for the $i$-th slot domain

The treatment of (25) yields to the following linear relation between the coefficient $A_{k}^{i}$ and the coefficients $A_{n}^{I}, B_{n}^{I}, C_{n}^{I}$ and $D_{n}^{I}$ defined above

$$
\begin{aligned}
& A_{k}^{i}=\sum_{n=1}^{\infty}\left(A_{n}^{I} \frac{2 R_{2}}{n \beta} \frac{P_{n}\left(R_{2}, R_{3}\right)}{E_{n}\left(R_{2}, R_{3}\right)}+B_{n}^{I} \frac{2 R_{3}}{n \beta} \frac{2}{E_{n}\left(R_{3}, R_{2}\right)}\right) \cdot f(k, n, i) \\
& +\sum_{n=1}^{\infty}\left(C_{n}^{I} \frac{2 R_{2}}{n \beta} \frac{P_{n}\left(R_{2}, R_{3}\right)}{E_{n}\left(R_{2}, R_{3}\right)}+D_{n}^{I} \frac{2 R_{3}}{n \beta} \frac{2}{E_{n}\left(R_{3}, R_{2}\right)}\right) \cdot g(k, n, i)
\end{aligned}
$$

We have to solve a system of five linear equations (A.7), (A.8), (A.11), (A.12) and (A.13) with five unknowns. By rewriting the above equations in matrix and vectors form, a numerical solution can be found by using mathematical software (Matlab or Maple).

\section{REFERENCES}

[1] S. J. Farlow, Partial Differential Equations for Scientists and Engineers. Dover publications, New York, 414 pp, 1993.

[2] Z. Q. Zhu and D. Howe, "Instantaneous magnetic-field distribution in brushless permanent-magnet dc motor, part III: Effect of slotting," IEEE Trans. Magn., vol. 29, no. 1, pp. 143-151, Jan. 1993.

[3] D. Zarko, D. Ban, and T. A. Lipo, "Analytical calculation of magnetic field distribution in the slotted air gap of a surface permanent-magnet motor using complex relative air-gap permeance," IEEE Trans. Magn., vol. 42, no. 7, pp. 1828-1837, Jul. 2006.

[4] M. Markovic, M. Jufer, and Y. Perriard, "Reducing the cogging torque in brushless dc motors by using conformal mappings," IEEE Trans. Magn., vol. 40, no. 2, pp. 451-455, Mar. 2004.

[5] K. Boughrara, D. Zarko, R. Ibtiouen, O. Touhami, and A. Rezzoug, "Magnetic field analysis of inset and surface-mounted permanentmagnet synchronous motor using Schwarz-Christoffel transformation," IEEE Trans. Magn., vol. 45, no. 8, pp. 3166-3168, Aug. 2009.

[6] P. Kumar, and P. Bauer, "Improved analytical model of a permanentmagnet brushless DC motor," IEEE Trans. Magn., vol. 44, no. 10, pp. 2299-2309, Oct. 2008.

[7] X. Wang, Q. Li, S. Wang, and Q. Li, "Analytical calculation of air-gap magnetic field distribution and instantaneous characteristics of brushles dc motors," IEEE Trans. Energy. Convers., vol. 18, no. 3, pp. 386-391, Sep. 2003.

[8] A. Radun, "Analytical calculation of the switched reluctance motor's unaligned inductance," IEEE Trans. Magn., vol. 35, no. 6, pp. 44734481, Nov. 1999.

[9] Q. Gu and H. Gao, "Effect of slotting in PM electrical machines," Elect. Mach. Power Syst., vol. 10, pp. 273-284, 1985.
[10] N. Boules, "Prediction of no-load flux density distribution in permanent magnet machines," IEEE Trans. Ind. Appl., vol. IA-21, no. 3, pp. 633643, Jul./Aug. 1985.

[11] K. F. Rasmussen, H. D. John, T. J. E. Miller, M. I. McGilp, and O. Mircea, "Analytical and numerical computation of air-gap magnetic field in brushless motors with surface permanent magnet," IEEE Trans. Magn., vol. 36, no. 6, pp. 1547-1554, Nov./ Dec. 2000.

[12] B. Ackermann and R. Sottek, "Analytical modeling of the cogging torque in permanent magnet motors," Elect. Eng., vol. 78, no. 2, pp. 117-125, Mar. 1994.

[13] Z. J. liu, and J. T. Li, "Analytical solution of air-gap field in permanent magnet motors taking into account the effect of pole transition over slots, " IEEE Trans. Magn., vol. 43, no. 10, pp. 3872-3882, Oct. 2007.

[14] Z. J. liu, and J. T. Li, "Accurate prediction of magnetic field and magnetic forces in permanent magnet motor using an analytical solution," IEEE Trans. Energy. Convers., vol. 23, no. 3, pp. 717-726, Sept. 2008.

[15] Z. J. Liu, J. T. Li, and Q. Jiang, "An improved analytical solution for predicting magnetic forces in permanent magnet motors," Journal of Applied Physics, vol. 103, no. 7, 2008.

[16] Z. Q. Zhu, S. Ruangsinchaiwanich, and D. Howe, "Synthesis of cogging-torque waveform from analysis of a single stator slot," IEEE Trans. Ind. Appl., vol. 42, no. 3, pp. 650-6571, May 2006.

[17] I. Boldea, Reluctance Synchronous Machines and Drives. Oxford Univ. Press, London, U. K., 1996.

[18] K. Atallah and D. Howe, "A novel high-performance magnetic gear," IEEE Trans. Magn., vol. 37, no. 4, pp. 2844-2846, Jul. 2001.

Manuscript received June 23, 2009. Corresponding author: Thierry Lubin (e-mail: thierry.lubin@green.uhp-nancy.fr).

Thierry Lubin was born in Sedan, France, in 1970. He received the M.S. Degree from the University of Paris 6, France in 1994 and the Ph.D. degree from the University Henri Poincaré, Nancy, France, in 2003.

$\mathrm{He}$ is currently a lecturer of Electrical Engineering at the University of Nancy at the Groupe de Recherche en Electrotechnique et Electronique de Nancy. His interests include modeling and control of electrical machine and applied superconductivity in electrical devices.

Smail Mezani was born in Algiers, Algeria, in 1974. He received the engineer diploma and the magister degree from the University of Sciences and Technology Houari Boumediene, Algiers, Algeria in 1996 and 1999 respectively. He obtained the $\mathrm{Ph} . \mathrm{D}$. degree from the Institut National Polytechnique de Lorraine, France, in 2004.

From 2004 to 2005, he was a Research Associate in the Department of Electronic and Electrical Engineering at the University of Sheffield, UK, where he worked on magnetic gears and "pseudo" direct drive electrical machines.

He is currently a lecturer at the University Henri Poincaré of Nancy, France, at the Groupe de Recherche en Electrotechnique et Electronique de Nancy where his research interests include the applications of superconductors in electromechanical devices.

Abderrezak Rezzoug received the Doctorat d'Etat from the Institut National Polytechnique de Lorraine, France, in 1987.

After working at the INPL as an assistant Professor until 1991, he joined the Université Henri Poincaré, Nancy, France, as a Professor. His interests are in superconducting applications to electrical devices, and the control and diagnosis of electrical machines. 